\title{
Realist, Non-Naturalist Ethics and Librarianship
}

\begin{abstract}
The fundamental premise of this paper is that the work of information professionals relies upon, and is an extension of, memory. Memory is an essential element in shaping consciousness, so it is likewise essential to information work. The place the past occupies is a complex one, as will be demonstrated in the presentation. The past cannot simply be categorized as history, since "history" depends on agency beyond the individual information professional. Models offered by Bergson and Wilson will bring the complexity to the fore and will illustrate how information professionals rely on memory for the most fundamental aspects of information work.
\end{abstract}

Ethics is not a science, nor can it be considered naturalistic. This claim is at the heart of the present proposal. Yet, the claim is not sufficient; it must be accompanied by a positive statement. That statement holds that ethics is real (there is the possibility of a realist, objective conception of ethics), and it is non-naturalistic. The initial claim will be addressed first here, and will be grounded in the discourse of librarianship. A salient point that is made by Shafer-Landau (2003) is that scientific facts are discovered by a posteriori means; observation is fundamental, even in the presence of hypotheses. As Shafer-Landau (2003) argues (convincingly), ethical and moral facts cannot be gleaned through observation; they depend upon a priori analysis (p. 61). It must be admitted at this time that the realist stance is distinct from consequentialism. That is, the determination of a moral fact is prior to the examination of the consequences of human actions. It is not that consequences are irrelevant; rather, the consequences should be able to be anticipated by the articulation of moral facts.

Consequentialism should be considered naturalistic; it is the result of decision processes that are similar to, and in keeping with, the natural sciences. If consequentialism obtained, ethical and moral facts would be in concert with the naturalism of, say, physics. Shafer-Landau (2003), and others, reject this relationship by denying that ethical and moral facts depend upon naturalistic causes and consequences. Shafer-Landau (2003) emphasizes a particular point of difference between naturalists and non-naturalists:

the debate between naturalists and non-naturalists has usually been cast as a metaphysical debate. Such debates often have epistemological implications, of course, but (as any realist will insist) we can and should avoid running metaphysical and epistemological issues together. ... [T] he essence of a natural property is that the fundamental truths that describe its nature, and the conditions under which it is instantiated, are discoverable in an exclusively a posteriori way (p. 61).

If the last sentence were true, there would be no metaphysical basis for ethical and moral facts.

There is another problematic that has to be considered, and it is related to the naturalist and a posteriori stance. If there is skepticism relating to ethical and moral facts, then there must be a relativism - a stance-dependence - at work. Timmons (1999) and Blackburn (1998) are, in effect, ethical nihilists; they do not admit to any possibility of a priori formation of ethical and 
moral facts. If they, and other relativists, are correct, then they must reject the possibility of ethical justification (something that is necessary for realism.

At this point there needs to be some description of the workings of moral realism and objectivity. Fortunately, Huemer (2013) provides background:

there are some objective moral reasons; that is, there are at least some objective facts of the form "S has a moral reason to $\Phi$." What is objectivity? A fact is said to be objective when it obtains independent of the attitudes of observers - for instance, independent of whether observers want it to obtain, whether observers value the fact, and so on (p. 261). The observer-independence is at the heart of both objectivity and realism. We should be able to take a statement or a proposition as they are and evaluate human action accordingly. Huemer (2013) summarizes his point, and that summary is accepted with respect to moral realism: "there are first-person, non-selfish, observer-independent reasons for action. This results merely from the fact that we have some epistemic reason to believe that certain actions are objectively right or wrong” (p. 277).

One of the principle objections to moral realism is that of empiricism. That is, there must be unobjectionable, evidence-based, particularist reasons for accepting moral claims and propositions. Ross (1988) counters the empiricist stance by saying that we have access to moral facts by means of access to intuitions (p. 29). One can interpret Ross's position as phenomenological, accepting Husserlian intuition. Meyers ((2013), asserts that Ross's stance as consistent with "considerable cross-cultural disagreement over all-things-considered judgments" (p. 384; emphasis in original). Meyers argues in favor of a pluralistic moral realism which takes agreement over type actions, while accepting disagreement over token actions. In other words, the fundamental principles are points of agreement, even though there may be some disagreement over specific actions that fall under the fundamental principles. Before delving more deeply into potential of pluralist moral realism, let us examine some claims of librarianship.

The primary document that should be considered in the context of this proposal is ALA's Code of Ethics. The first four tenets of the Code are:

I. We provide the highest level of service to all library users through appropriate and usefully organized resources; equitable service policies; equitable access; and accurate, unbiased, and courteous responses to all requests.

II. We uphold the principles of intellectual freedom and resist all efforts to censor library resources.

III. We protect each library user's right to privacy and confidentiality with respect to information sought or received and resources consulted, borrowed, acquired or transmitted.

IV. We respect intellectual property rights and advocate balance between the interests of information users and rights holders (American Library Association, Code of Ethics).

Why do these tenets constitute realist, non-natural ethics? To begin with the realist element, we can explore the meaning of realism. Realism cannot be entirely separated from ontology, or the examination of what is real. Heil (2003) offers perhaps the most succinct description of what ontology is: 
Concepts do not "carve up" the world. The world already contains endless divisions, most of which we remain oblivious to or ignore. Some of these divisions, however, are salient, or come to be salient once we begin enquiring systematically. These are the divisions reflected in our concepts and in words we use to express those concepts" (p. 44).

The aspects of the Code include divisions, whether we acknowledge them explicitly or not. But we do - or should - enquire systematically into the essences of the Code. As we do enquire, we see certain ineluctable conclusions, which are articulated explicitly in the items in the Code. The individual items specify action that admits to presumptions of the nature of the world. Each of the four items mentioned above express something about the way the world is. Considerably more will be said about this relationship to ontology in the final paper.

Why non-naturalist? I agree with Shafer-Landau (2003) and his assertion that moral and ethical facts are not synonymous with physical facts. Above it is mentioned that ethical facts can be defined a priori; that is one of the key elements of the non-naturalist stance. Ethical and moral realism are, in large part, components of what can be called "the good life." The good life is neither utilitarian nor hedonistic. In fact, the good life, as a phenomenological construct, is imbued with concern, not only for the self, but for the other. Close examination of the Code of Ethics reveals this concern; the professional is to consider what is best for others (especially seekers and users of information - writ large). To be specific for a moment, intellectual freedom is, at root, an ethical commitment to (at least) two principles: (1) it is a fact that all people should have access to the information they seek, and (2) it is the professional's duty to assist information seekers in their quest to find information. The principles are, as can be seen from the aforementioned argument, a priori in nature; they do not rely upon observation or empiricism.

To return to an earlier point, the position of moral realism is pluralist in that the principles are to be considered types. When particular tokens are taken into account, specificity must enter the picture. To use an obvious example, the Code does not necessitate assisting with the quest for child pornography. Society has deemed that token of information illegal and immoral. As ShaferLandau (2003) says, "The pluralist picture doesn't seem profligate" (p. 76).

Within the pluralist limitation, though, moral realism does hold and the profession of librarianship does adhere to its conditions. 


\section{References}

American Library Association. Code of ethics of the American Library Association.

http://www.ala.org/advocacy/proethics/codeofethics/codeethics.

Blackburn, Simon. (1998). Ruling passions. Oxford: Oxford University Press.

Heil, John. (2003). From an ontological point of view. Oxford: Oxford University Press.

Huemer, Michael. (2013). An ontological proof of moral realism. Social Psychology \& Policy Formation 30(1-2), 259-79.

Meyers, C. D. (2013). Defending moral realism from empirical evidence of disagreement. Social Theory and Practice 39(3), 373-96.

Ross, W. D. (1988). The right and the good. Indianapolis: Hackett.

Shafer-Landau, Russ. (2003). Moral realism: A defence [sic]. Oxford: Clarendon Press.

Timmons, Mark. (1999). Morality without foundations. Oxford: Oxford University Press. 